\title{
Prospecting for
}

Uranium With

Car-Mounted

Equipment

GEOLOGICAL SURVEY BULLETIN 988 -I

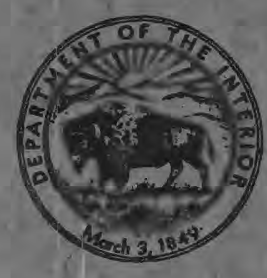




\section{Prospecting for \\ Uranium With}

\section{Car-Mounted}

Equipment

By JOHN M. NELSON

A CONTRIBUTION TO THE GEOLOGY OF URANIUM

GE O L O G I C A L S U R VEY B U L L E T I N $988-$ I

This report concerns work done on behalf of the U.S. Atomic Energy Commission and is published with the permission of the Commission

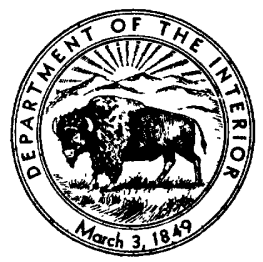




\section{UNITED STATES DEPARTMENT OF THE INTERIOR}

Douglas McKay, Secretary

\section{GEOLOGIGAL SURVEY}

W. E. Wrather, Director 


\section{CON'TENTS}

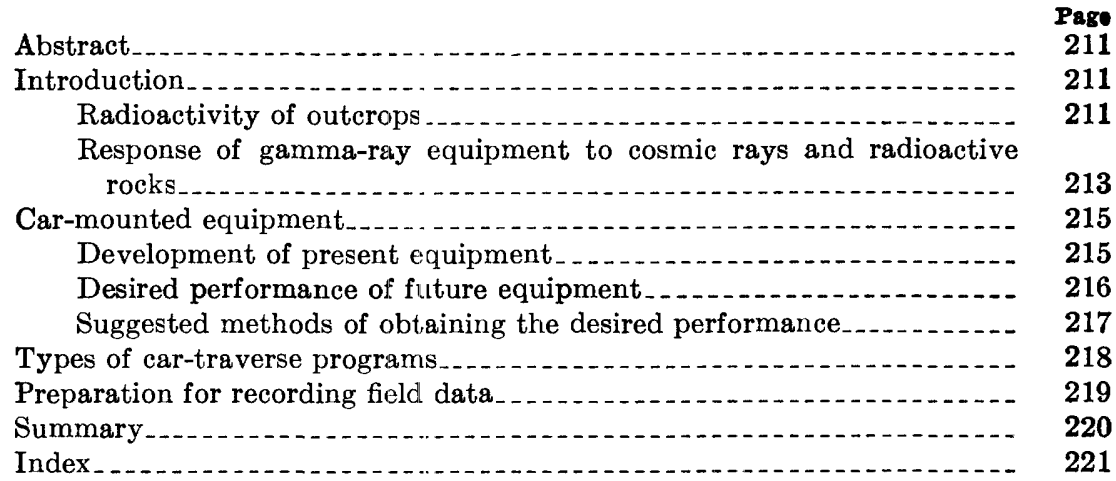

\section{IILUSTRATIONS}

FIGURE 50. Frequency distribution of radioactivity intensities from outcrops _. . . .

51. Gamma field of radioactive outcrop and response of carmounted Geige r-Mueller counter...........................

52. Diagram of components of car-mounted instruments.......

53. Schematic diagram of alarm circuit. . 



\title{
A CONTRIBUTION TO THE GEOLOGY OF URANIUM
}

\section{PROSPEGTING FOR URANIUM WITH GAR-MOUNTED EQUIPMENT}

\author{
By John M. Nelson
}

\begin{abstract}
The U. S. Geological Surrey has prospected for uranium with a car-mounted Geiger-Mueller counter since 1945. The basic principles of the car-traverse technique are simple. Rocks and soils of abnormally high uranium or thorium content are surrounded by an equivalently high gamma radiation field. An abnormal gamma-radiation field that extends across a road or highway can be detected at relatively high speeds by a car or truck equipped with a suitable Geiger-Mueller counter. (nnce detected by car-traversing, the deposit can be examined with light portabie instruments, and the better portions sampled. The prime advantage of the car-traverse technique is the rapidity of the scanning yrocess, 100 to 200 miles per day, which permits exploration of large areas in a short time.
\end{abstract}

\section{INTRODUCTYON}

\section{RADTOACTIVITY OF OUTCROPS}

Commercial production of portable radioactivity detectors opened the way for prospecting on foot without exhaustive sampling. Recent improvements in equipment permit detection of radioactive deposits from a moving car, train, or boat. The objective is the fastest and most productive method of detecting radioactive deposits in a given area.

Experiments by the U. S. Geological Survey with car-mounted Geiger-Mueller counters began in 1945 and have continued through 1949. Standard equipinent, modified for the car-traverse technique, has been used wherever possible. In this report, the results of the experiments are presented, the instruments described, and operational procedures are suggested.

The frequency distribution of radioactivity intensities of 2,200 outcrops of sedimentary, metamorphic, and igneous rocks in an area of 30,000 square miles is illustrated in figure 50 . The radioactivities of nearly all outcrops in this area range from 0.0002 to 0.004 percent equivalent uranium. Radioactivities in this range are called normal and do not aid the prospector searching for a uranium deposit. Few 


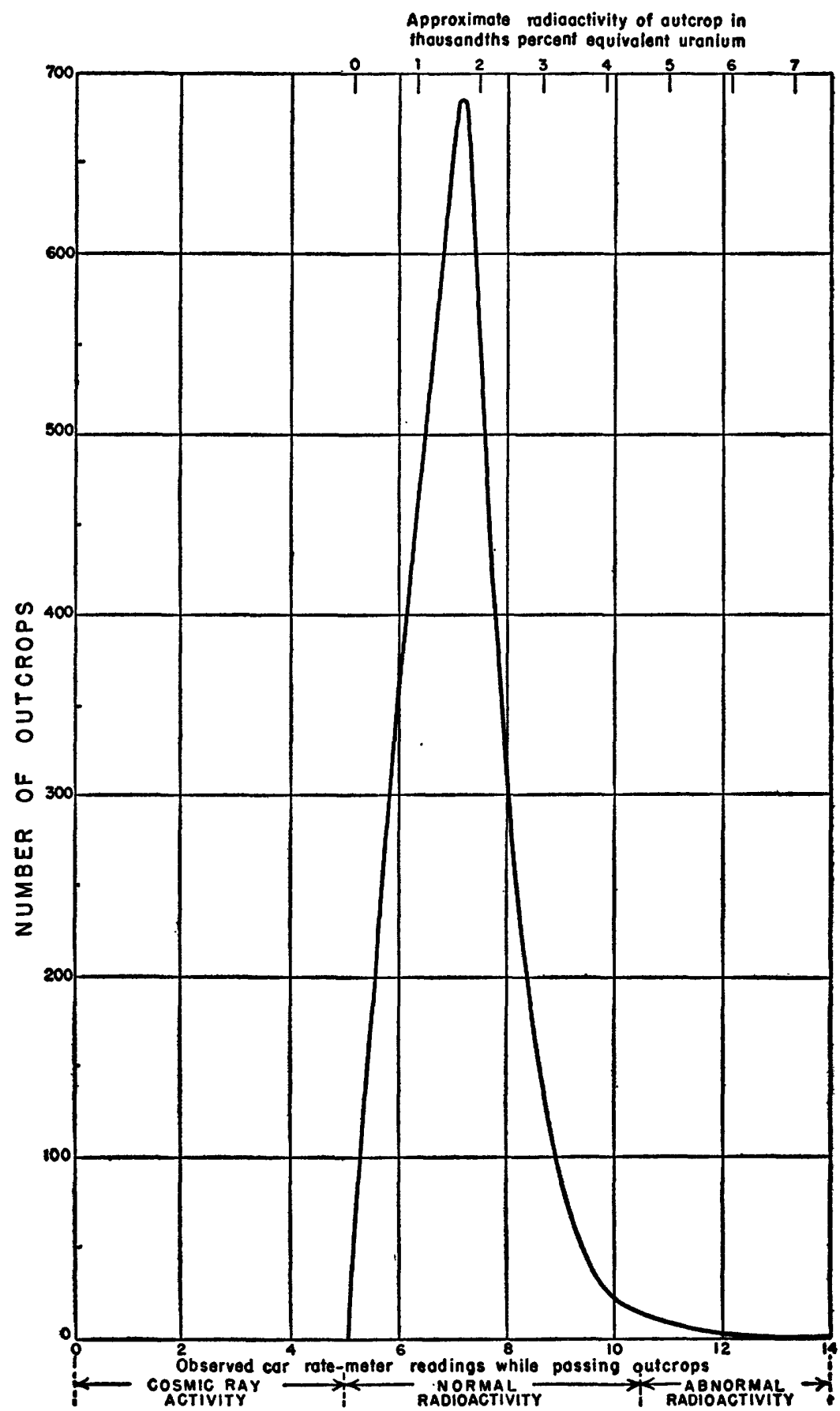

Frave 50.-Frequency distribution of radioactivity intensities from outcrops. 
rocks in the area have a radioactivity of 0.005 percent equivalent uranium or more. Radioactivities in this higher range are called abnormal and indicate an abnormally high concentration of uranium or thorium in the rock.

\section{RESPONSE OF G.AMMA-RAY EQUIPMENT TO COSMIC RAYS AND RA.DIOAC'IIVE ROCKS}

Gamma-ray equipment responds to both cosmic rays originating in outer space and gamma rays originating in substances in the vicinity of the instrument and to radiation from internal contamination of counter. The response to cosmic rays for an instrument, at a given elevation above sea level, and at a given latitude may be determined by noting the instrument response over essentially nonradioactive water of a depth of 10 feet or more, at a considerable distance from shore. The response to cosmic rays may be determined with less accuracy by noting the lowest consistent response while carrying the instrument across a thick section. of sandstone, limestone, or basalt, which are generally of very low radioactivity. These measurements of cosmic-ray activity (the basic response) also include the minor radioactivity originating in the air and the instrument.

Responses in excess of the basic response are caused by radioactive rocks, soils, or other substances near the instrument and directly reflect the degree of radioactivity. The degree of instrument response in excess of basic response is the quantity to be measured by the prospector.

The response of gamma-ray equipment to a given source of radioactive material is a function of (1) the solid angle between the source material and the detector and (2) the absorption of gamma rays by the intervening air. The solid angle is subtended, from the instrument at the apex, by the boundaries of the surface of the source material.

The instrument response varies directly with the size of the solid angle between the instrument and the radioactive source material. The response is greatest in underground workings or in a highway tunnel, where the solid angle between instrument and radioactive source material is largest. The response is only one-half as great for the same source material on a level plain where the solid angle is half as large. The instrument response is extremely small for source material of the same radioactivity where the instrument is many feet from a few square inches of the exposed radioactive outcrop as the solid angle decreases with the square of the distance.

In addition to the effect of solid angle, the amount of intervening air lowers the instrument response, because it absorbs gamma radiation. At a distance of about 400 feet, about one-half of the gamma rays emitted by the uranium series are absorbod, and the instrument 


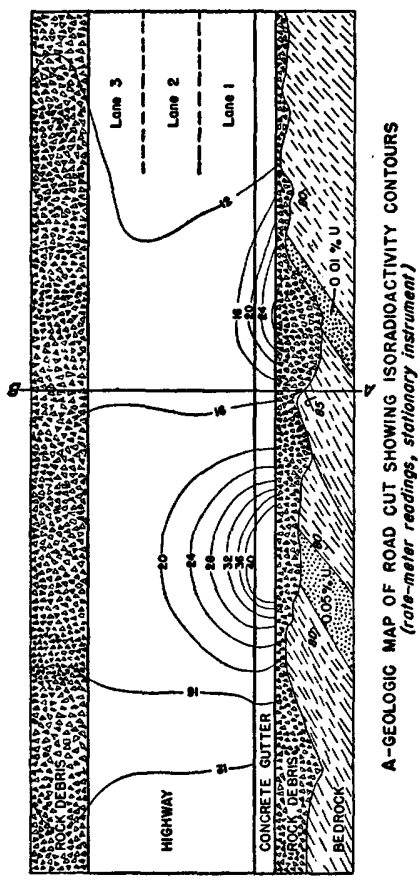

OVO ININOW NI LNJWกYISN SONIOVJY $8313 w-317 Y$
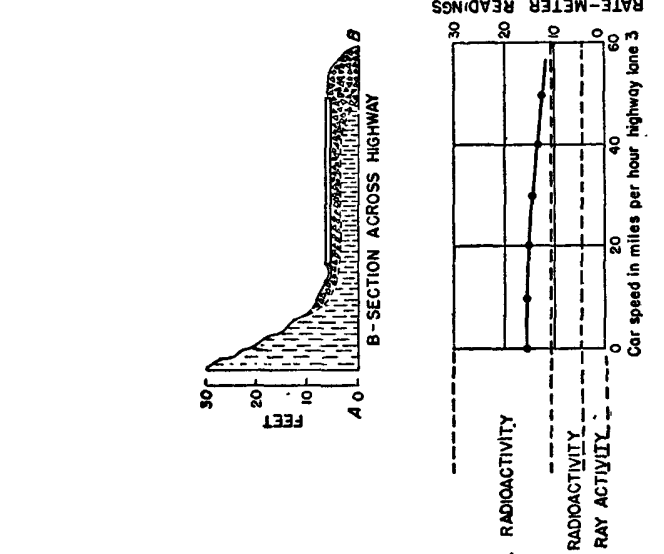

YVO INHOW M INZWกYISN

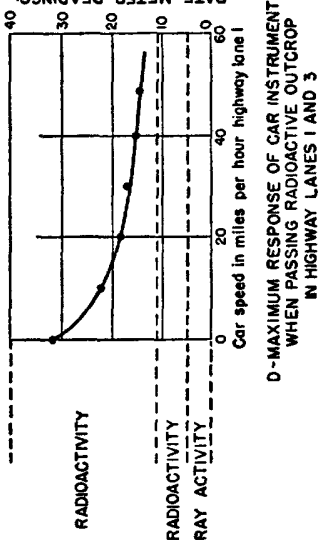

范

'通
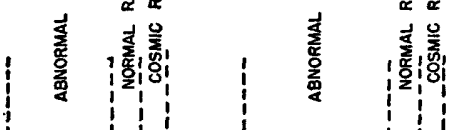

8

$\%$ 吾

虽 \&

11

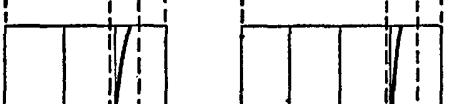

造

8

- 
response is reduced proportionally. For practical purposes, the limit of detection of extremely large high grade deposits is about 1,000 feet in air.

Where the gamma-radiation field of a uranium deposit extends across a road or highway, it can be detected by equipment mounted on a moving car or truck. The gamma-radiation field of a deposit discovered while car-traversing at a speed of 30 miles per hour is shown in figures 51A and 51B.

\section{CAR-MOUNTED EQUIPMENT}

\section{DEVELOPMENT OF PRESENT EQUIPMENT}

The car-traverse technique was first used by A. L. Slaughter and John M. Nelson of the U. S. Geological Survey in 1945. The instrument consisted of a Geiger-Mueller counter with a response of 12 pulses per minute in an environment of average activity, a small amplifier, and a pair of earphones. At normal driving speeds, this instrument detected several radioactive roadside deposits, although the pulse rate was too low for the desired accuracy.

In 1946-47, a larger Geiger-Mueller tube, having a response of 500 pulses per minute, feeding into a counting-rate meter, was used. With this instrument, several new radioactive deposits were detected. The pulse rate was still too low for the desired accuracy, and the time constant of the counting-rate-meter circuit, 1 minute, was too long for fast traversing.

In 1948, improved equipment was used. Two Geiger-Mueller tubes, each having a response of 1,500 pulses per minute, were connected to a counting-rate-meter circuit with a time constant of about 2 seconds.

One Geiger-Mueller tube was attached to each side of a panel delivery truck. The counting-rate assembly was placed in a convenient position between the two seats, and an alarm circuit was located behind the driver's seat. The general layout of the units is shown in figure $\mathbf{5 2}$.

The alarm circuit (fig. 53), designed and constructed by Donald H. Johnson of the Geological Survey, is connected across the countingrate microammeter. The voltage across the microammeter varies directly with the response of the instrument to a radioactive field. The alarm circuit amplifies the voltage difference across the meter and operates a bell-ringing relay. The alarm can be adjusted to ring at any desired reading of the counting-rate meter. The automatic alarm circuit permits the geologist to observe the roadside rocks.

Three panel delivery trucks outfitted with this equipment were operated in the late summer and fall of 1948. The usefulness and limitations of this instrument are graphically shown in figures 51C and $51 \mathrm{D}$.

Figure 51C shows the gamma-radiation field through which the truck traveled on two highway lanes; figure 51D shows the response 


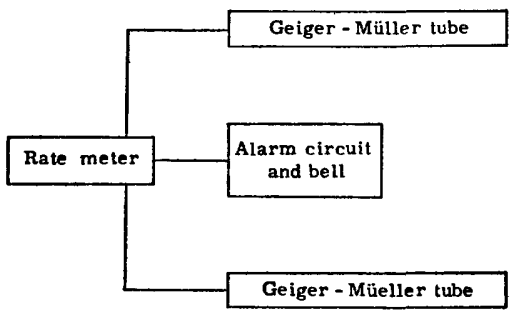

\section{EXPLANATION}

Geiger - Müller tubes are brass cathodes, 2 in. in diameter and $42 \mathrm{in.}$ long, mounted on the exterior of car as high as possible

Rate meter modified for use with the large Geiger Muiller tubes by addition of batteries to produce 1120 volts. The instrument is mounted inside the car where the microammeter can be easily read by the operator

Alarm circuit and bell are mounted inside the car conveniently close to the operator

Figure 52.-Diagram of components of car-mounted instruments.

of the instrument to the radioactive field at several car speeds. While passing the radioactive deposits at speeds of less than 10 miles per hour, the response of the car-mounted instrument closely approaches the maximum value of the gamma-radiation field through which it passes. At progressively higher speeds, the instrument response decreases because the counters do not remain in the radiation field long enough to allow the rate meter to reach equilibrium. Although the response of this instrument is sufficient to trigger the alarm circuit at speeds as much as 50 miles per hour in highway lane 3 and at an estimated speed of as much as 80 miles per hour in highway lane 1, smaller deposits located farther from the road might remain undetected by the instrument.

\section{DESIRED PERFORMANCE OF FUTURE EQUIPMENT}

The performance requirements of future equipment are based on three factors: (1) desired reproducibility of measurements, (2) length of traverse per individual measurement, and (3) speed of vehicle travel.

The desired reproducibility of measurement is a standard deviation of plus or minus 10 percent. As the standard deviation in percent roughly equals $\frac{\sqrt{N}}{N} \times 100$, where $N$ is the total number of pulses in

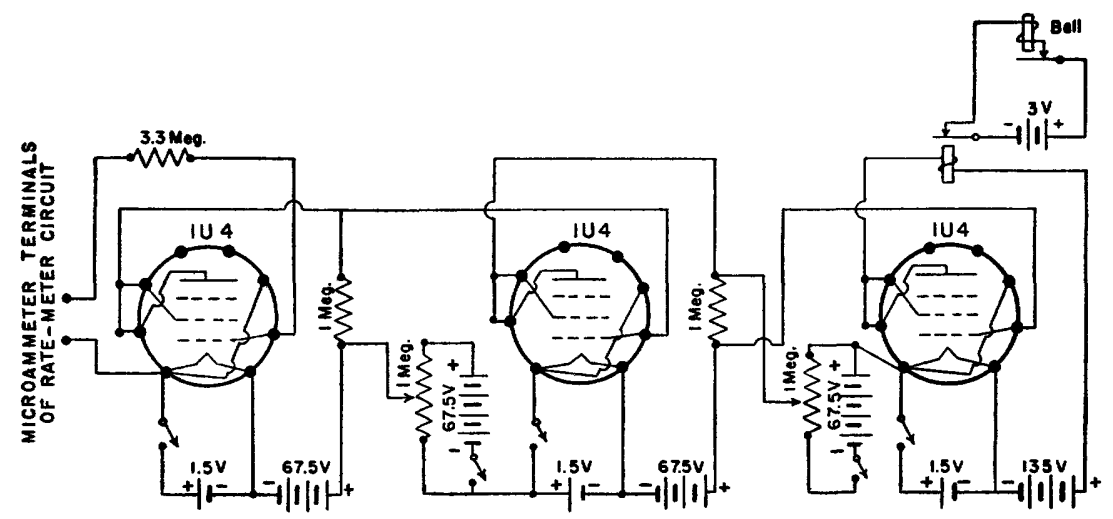

Figure 53.- Schematic diagram of alarm circuit. 
the measurement, a standard deviation of 10 percent requires a minimum of 100 pulses per measurement. Figure 50 shows that this degree of reproducibility is adequate to detect significant abnormalities.

The length of traverse during which the radioactivity of the environment is measured is based on the minimum width of an abnormal gamma-radiation field through which the equipment might pass. A consecutive series of individual measurements, each giving the average radioactivity of a 10 -foot traverse interval, is considered adequate for the detection of the deposit shown in figure $51 \mathrm{~A}$ and for smaller deposits.

The maximum speed of vehicle travel is limited by human factors. Field experience shows that the geologist observer can usually identify the roadside rocks up to speeds of 30 miles per hour, if he stops to check his identification when in doubt.

These considerations indicate that the desired equipment should be capable of a pulse rate of 100 pulses per 10 -foot interval. At a speed of 30 miles per hour, the 10-foot intervals are traversed in about one-fifth second and the desired pulse rate for areas of normal radioactivity is 100 pulses per one-fifth second or 30,000 pulses per minute.

\section{SUGGESTED METHODS OF OBTAINING THE DESIRED PERFORMANCE}

Although the instruments described in this paper have proved their value in prospecting for radioactive source materials, they are essentially simple and crude. Many necessary improvements can be made.

First, the desired pulse rate of 30,000 pulses per minute can be obtained by in-parallel coupling of 20 brass-walled Geiger-Mueller tubes, 42 inches in length and 2 inches in diameter. These tubes are produced commercially and are available.

Second, the desired speed of response, sufficient to give a continuous series of radioactivity measurements, can be obtained either by decreasing the time constant of a counting-rate-meter circuit or by using a scaler circuit, at a scale of 100 . If using the scaler circuit, each hundredth pulse could be recorded on rnoving tape by means of electric sparks or other means and the distance between spark holes on the tape would vary inversely with the radioactivity. Other methods of obtaining fast instrumental response will be obvious to personnel trained in electronics.

The position of the Geiger-Mueller tubes on the vehicle is important. The highest possible location of the tubes on or above the vehicle will permit the greatest instrumental response because of the larger solid angle between Geiger-Mueller tubes and roadside rocks. However, low bridges over roads limit the practical height of the tubes from 7 to 10 feet above road level, depending on the region. 
The response of the instrument to the roadside rocks is also dependent on the geometric arrangement of the gamma tubes. The objective is to arrange the tubes so that they will be actuated to the fullest degree by gamma rays emitted from the roadside rocks and to the least extent by gamma rays emitted from the underlying road materials and by cosmic rays descending from above. The simplest efficient arrangement is obtained by forming a single vertical bank of 20 contiguous tubes, symmetrically mounted above the vehicle, with the axes of the tubes horizontal and parallel to the travel path of the vehicle. The tubes in this position present the largest target for gamma rays emitted from the roadside rocks, and one of the smallest targets for gamma rays emitted by the road materials and for cosmic rays for above. This arrangement also decreases the percentage of coincidence counts from the roadside, and increases the percentage from above and below. Moreover, the vehicle partly shields the tubes from the gamma rays emitted from the road materials and reduces the number of these gamma rays that reach the tube.

Preferential response of the instrument to gamma rays emitted by roadside rocks over those emitted by the road material and cosmic rays may also be obtained by the use of coincidence and anticoincidence circuits, with a variety of gamma-tube arrangements. The increased complexity of such circuits may or may not ontweight their advantages. Their relative merits cannot be evaluated until they are used in the field.

\section{TYPES OF CAR-TRAVERSE PROGRAMS}

The car-traverse technique has several applications. Its most important use is fast reconnaissance of large untested areas. Other uses are: Exploration in a wide area around known deposits, traversing to and from mining properties, and objective exploration of all rocks and soils in areas where the most favorable rocks have already been examined.

Car-traversing, with its high speed of 100 to 200 miles per day, makes it possible to sample large areas of untested rocks in a short time. Its ability to detect the few abnormally radioactive rocks and soils in such an area gives a relatively complete radioactivity profile along the roads traversed.

The car-traverse technique may also be used to explore a wide area around a known radioactive deposit; its speed and low cost permit exploration extending beyond the limits of the more common exploration techniques.

A field party using this technique in the general vicinity of a deposit in conglomerate discovered a second deposit in a sandstone of widely different age. The objective scanning of all roadside rocks 
made possible a discovery that would not have occurred by routine examination of this and adjacent formations.

The technique has been used successfully on routine trips to and from mining properties and otleer specific points of interest. The value of this use of the technique lies in the utilization of normal travel time to test roadside rocks and soils that would not otherwise be investigated. A number of abnormally radioactive rocks were discovered in this manner in 1945, 1946, and 1947.

Even though the most favorable rocks in an area have already been examined, the objective exploration of less favorable rocks and soils has proved profitable. While driving through an area of known radioactive minerals, one car-traverse party discovered an additional highly radioactive soil zone.

\section{PREPARATION FOR RECORDING FIELD DATA}

Regardless of the use to which the car-traverse technique is put, the following preparation is required if the field party is to take full advantage of the potential rapidity of the technique.

The area to be investigated must be selected and limited after consideration of its geology. It should be subdivided into geologic divisions of varying promise, and the tentative time of exploration in each subdivision should be allotted accordingly. The geologic information of the area should be studied and indexed for field use. The field parties have found it most convenient to have all pertinent data plotted on index maps. Known localities of radioactive rocks and localities of special geologic interest may be plotted on one index map; parts of the area covered by geologic maps may be plotted on a second; parts of the area described in publications may be plotted on a third. The speed with which the car-traverse technique can be employed is such that the field party may find that it has passed within a mile or two of a point of interest after it is several hundred miles beyond the point, unless all information is available in simplified form.

In addition to the car-mounted equipment, the party requires a portable garnma counting-rate meter of normal pulse rate, 1,000 or more pulses per minute, for detailed scanning of localities found by the car-traverse technique; a portable scaler and a jaw-crusher are desirable for determining the radioactivity of samples. Equipment for determining the radioactivity of the samples to the nearest thousandth percent equivalent uranium, while at the radioactive locality, permits the field party to make an immediate decision on the length of time to be allotted to local examination. If the field party waits for quantitative results obtained from the laboratory, it may find itself hundreds of miles from the locality, and may have to return to 
it, or it may find that an unjustified amount of time has been spent at a locality of low-grade rock.

The parties also require three standard samples (low-, medium-, and high-grade) that have the density of common rocks and are crushed to the same size as the samples collected in the field. The standard samples should consist of uranium in equilibrium with its daughter elements, thoroughly mixed with a diluent of average rock density. Pitchblende mixed with nonradioactive portland cement, cast and crushed to the proper size, has proved satisfactory.

The personnel required depends on the type of equipment and the information desired. A two-man party is generally desirable, but if the equipment includes an adjustable alarm, or if the radioactivity is automatically recorded and a continuous record of the geology is not required, one man can do the job. The personnel should be trained in maintenance and repair of the electronic equipment.

If the prospecting is on a large scale, the specially equipped car may be kept in the field throughout the year by the interchange of parties between the field and the office. If the prospecting is on a smaller scale and no replacements are available, the car-traverse party will probably do the detailed mapping of the radioactive localities.

Recording of car-traverse data may be simple or complex. In their simplest form the data consist of the roads traversed, recorded in pencil or ink directly on a road map, together with the exact location of any locality of sufficiently high radioactivity to interest the observer. A more complete recording of data would include, in addition to the foregoing, a complete radioactivity profile of the road traversed and the geology. This latter type of recording has the advantage of preserving smaller peaks of radioactivity, which, when integrated from one road to another, may indicate an intervening area of promise. However, this complex system of recording has the disadvantage of accumulating tremendous amounts of data that require a long period for analysis.

\section{SUMMARY}

Active field work has shown many advantages of the car-traverse technique over spot examination of outcrops with the hand counter. The coverage of 100 to 200 miles of roadside rocks and soils per day permits sampling of large untested areas that could not be investigated in a reasonable length of time by slower methods. The continuous and objective scanning of all rocks and soils along the routes traveled has disclosed uranium in rocks previously believed to be essentially barren. This objective characteristic of the technique is of considerable importance, because the use of uranium as a source material for atomic energy has created a demand for uranium ores, whose associations and distribution are not completely known. 


\section{N D E X}

Page Page

Alarm circuit_........................ 215, 216, 220 Limit of detection of high-grade deposits..... 215

Application of car-traverse technique . . 215, 218-219 Performance ............................ 216

Cosmic rays . ......................... 212-213 Personnel required........................ 220

Counting-rate meter................... . 215, 219 Position of tubes on vehicle................ 217-218

Detection of radioactive deposits.

211, 215 Radioactivity intensities.

211,213

Effect of solid stngle

Instrument res ponse, arrangement of tubes for. $\quad 218$ pulse rate

variation

219 Selection of area . . . . . . . . . . . . . . . . . . . 219

Speed of vehicle................... 215, 216, 217

Standard deviation formula. . . . ............. 216

Length of traverse. 



\section{Contributions to the Geology of Uranium}

GE OL O G I A A S U R V E Y B U L L E T I N 988

This bulletin was printed as separate chapters, $A-I$, inclusive

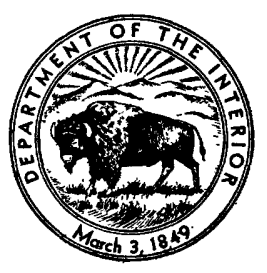


UNITED STATES DEPARTMENT OF THE INTERIOR

Douglas McKay, Secretary

GEOLOGIGAL SURVEY

W. E. Wrather, Director 


\section{CONTENTS}

[The letters in parentheses preceding the titles are those used to :designate the papers for separate publication]

Page

(A) Geology of the Uravan mineral belt, by R. P. Fischer and L. S. Hilpert_ 1

(B) Geologic guides to prospecting for carnotite deposits on Colorado Plateau, by D. B. Weir

(C) Uranium in the East Walker River area, Lyon County, Nev., by M. H. Staatz and H. L. Bauer, Jr.

(D) Distribution of uranium in rich phosphate beds of the Phosphoria formation, by M. R. Thompson. 45

(E) Radioactivity in some oil fields of southeastern Kansas, by G. B. Gott and J. W. Hill

(F) Uranium-bearing deposits west of Clancey, Jefferson County, Mont., by W. A. Roberts and A. J. Gude 3d

(G) Geology of the area adjacent to the Free Enterprise mine, Jefferson County, Mont., by W. A. Roberts and A. J. Gude 3d

(H) Uranium and thorium deposits in east-central Idaho and southwestern Montana, by A. F. Trites, Jr., and E. W. Tooker........

(I) Prospecting for uranium with car-mounted equipment, by J. M. Nelson. 



\section{CONTENTS}

[Chapter $\mathrm{F}$ was originally published as pages 69-87. Please insert corrected page numbers according to the following table of contents and index]

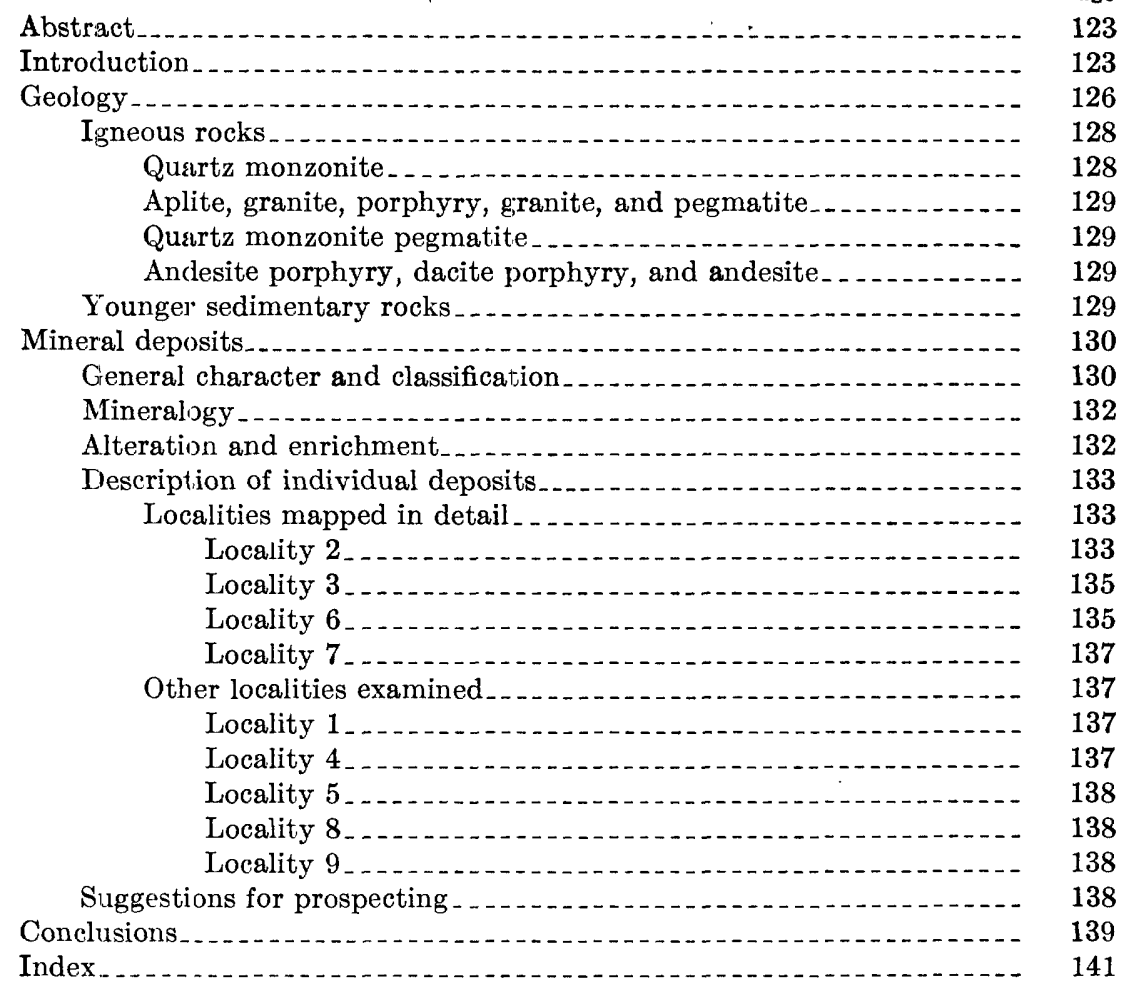

\section{ILLUSTRATIONS}

Plate 18. Geology of area containing uraniferous deposits west of Clancey, Jefferson County, Mont........................... In pocket

19. Geologic map of locality 2 ........ In pocket

20. Geologic map of locality 3...... In pocket

21. Geologic map of localities 6 and 7. . . .

Figure 34. Index map showing area mapped near Clancey, Jefferson

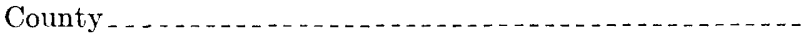

35. Index map showing areas mapped in detail and radio-

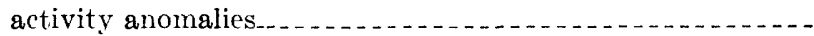

36. Jiagrammatic section illustrating four ages of silica. . . . . . 127 



\section{N D EX}

\begin{tabular}{|c|c|}
\hline Page & Page \\
\hline 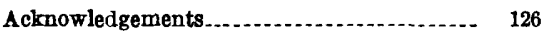 & Locality 4 \\
\hline Alaskite & Locality $5 \ldots$ \\
\hline Alteration and enrichment & analyses of samples, uranium deposits. ... 136 \\
\hline Analyses of samples, uranium deposits ...... 136 & Locality $6 \ldots \ldots$ \\
\hline Andesite & analyses of samples, uranium deposits \\
\hline porphyry & geology \\
\hline Aplite. & Locality $7 \ldots \ldots \ldots$ \\
\hline Berman, Joseph, identiflcations by ......... 13:2, 134 & 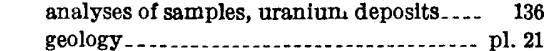 \\
\hline Boulder batholith & Locality 8 . $126,132,137,138$ \\
\hline region. & Locality $9 . \ldots$ \\
\hline Conclusions. & Mineral deposits. .......... \\
\hline Dacite... & Mineralogy \\
\hline porphyry . & New Stake mine. \\
\hline Dan Tucker mine & \\
\hline Description of deposits. & $\begin{array}{l}\text { Pegmatite } \\
\quad \text { quartz monzonite }\end{array}$ \\
\hline Free Enterprise mino....................... 133, 138 & Pitchblende \\
\hline uranium-silver ore & Production, value \\
\hline Geology & Prospecting, suggestions for \\
\hline Girhard, M. N., Indentiflcation by & Quartz monzonite \\
\hline Granite. & $127,128,130-131,134,135,137,138,139$ \\
\hline porphyry & composition, average ........... 128 \\
\hline Igneous rocks. & pegmatite \\
\hline King Solomon mine........... & $\begin{array}{r}\text { Radioactivity anomalies } \\
126,131,133 ; \text { pls. } 19,20,21\end{array}$ \\
\hline Little Nell mine........ 130 & Sedimentary rocks \\
\hline $\begin{array}{l}\text { Locality } 1 \\
\text { Locality } 2\end{array}$ & Silica \\
\hline $\begin{array}{l}\text { analyses of samples, uranium deposits. ... } 136 \\
\text { geology }\end{array}$ & Terrace gravels......... \\
\hline $\begin{array}{l}\text { Locality } 3 \text {. } \\
\text { analyses of samples, uranium deposits . }\end{array}$ & $\begin{array}{l}\text { Uranium minerals } \ldots . . . . . .126,127,130, \\
131,132-133,134,135,137,138,139\end{array}$ \\
\hline $\begin{array}{l}\text { analyses of samples, uranium deposits } \ldots \text { - } 136 \\
\text { geology }\end{array}$ & $\begin{array}{l}131,132-133,134,135,137,138,139 \\
\text { Uranium-silver ore, Free Enterprise mine } \ldots\end{array}$ \\
\hline
\end{tabular}



